\title{
A saúde mental para todos que bordeje o mal estar de cada um: a resistência da psicanálise as estratégias biopolíticas em psiquiatria ampliada
}

La salud mental para todos que alcance el mal estar de cada uno:

La resistencia del psicoanálisis a las estratégias biopolíticas em psiquiatría ampliada

The mental health for all that border the malaise of each one:

the resistance of psychoanalysis to biopolitical strategies in expanded psychiatry

Kelly Moreira de Albuquerque

Fanor-Devry-Ceará-Brasil

Clara Virginia De Queiroz Pinheiro

Universidade de Fortaleza - Ceará - Brasil

\section{RESUMO}

Os discursos em psiquiatria ampliada e seu projeto biopolítico de gestão das condutas não patológicas ocupam hoje um lugar hegemônico na problematização do sofrimento psíquico e dos modos de subjetivação nele entrelaçado. Assim, objetivamos, mediante a introdução de uma discussão sobre a dimensão ética em Psicanalise, apontar uma posição de resistência, sugerindo um modo diferenciado deste estabelecido pelo biopoder, para pensarmos o estatuto do sofrimento psíquico na atualidade.Constituímo-nos enquanto um estudo teórico conceitual orientado pela perspectiva genealógica de Michel Foucault. Composta por um conjunto de princípios metodológicos para a análise das formas do exercício do poder, a genealogia nos possibilita apreender a medicalização dos sofrimentos e comportamentos não patológicos, assim como a preocupação psiquiátrica pelos pequenos desvios e fracassos, como uma estratégia biopolítica. $\mathrm{O}$ discurso de ampliação da psiquiatria é produto de uma história atravessada por relações de poder, imprescindíveis à fabricação da subjetividade contemporânea. Absolutamente, só há poder porque há possibilidade de resistência. Por isso, inferimos, com a psicanalise, que o sofrimento psíquico constitui-se como um antipoder dos indivíduos em face do poder psiquiátrico e seu processo normalizador.

Palavras-chave: Psiquiatria ampliada. Biopolítica. Sofrimento psíquico. Subjetividade. Psicanálise.

\section{RESUMEN}

Los discursos em psiquiatría ampliada y suproyecto biopolítico de gestión de las conductas no patológicas ocupanhoy un lugar hegemónico em la problematización del sufrimiento psíquico y de los modos de subjetivación em élentrelazado. Así, objetivamos, mediante la introducción de una 
discusión sobre la dimensión ética em Psicoanalisis, apuntar una posición de resistencia, sugiriendo un modo diferenciado de lo establecido por el biopoder, para pensar sobre nuestra relación com el sufrimiento psíquico en la actualidad. Nos constituimos como um estudio teórico conceptual orientado por la perspectiva genealógica de Michel Foucault. Comenzada por un conjunto de principios metodológicos para el análisis de las formas del ejercicio del poder, la genealogía nos permite aprehender la medicalización de los sufrimientos y comportamientos no patológicos y la consiguiente preocupación psiquiátrica por los pequeños desvíos y fracasos como una estrategia biopolítica. El discurso de ampliación de la psiquiatría es producto de una historia atravesada por relaciones de poder imprescindibles a la fabricación de la subjetividad contemporánea. Absolutamente, solo hay poder porque hay posibilidad de resistencia. Por eso, inferimos, com la psicoanalisis, que el sufrimiento psíquico se constituye como um antipoder de los individuos frente al poder psiquiátrico y suproceso normalizador.

Palabras clave: Psiquiatría ampliada. Biopolítica. Sufrimiento psíquico. Subjetividad. Psicoanálisis.

\begin{abstract}
The discourses in expanded psychiatry and its biopolitical project of management of nonpathological behaviors today occupy a hegemonic place in the problematization of psychic suffering and modes of subjectivation. Thus, we objectify, through the introduction of a discussion on the ethical dimension in Psychoanalysis, point to a position of resistance, suggesting a different way of this established by the biopoder, to think about our relationship with psychic suffering today. We are constituted as a conceptual theoretical study guided by the genealogical perspective of Michel Foucault. Composed of a set of methodological principles for the analysis of the forms of the exercise of power, the genealogy enables us to grasp the medicalization of non-pathological sufferings and behaviors and the consequent psychiatric concern for small deviations and failures as a biopolitical strategy. The discourse of expansion of psychiatry is the product of a history crossed by power relations essential to the fabrication of contemporary subjectivity. Absolutely, there is only power because there is possibility of resistance. For this reason, we infer from psychoanalysis that psychic suffering constitutes an antipower of individuals in the face of psychiatric power and its normalizing process.
\end{abstract}

Keywords: Expanded psychiatry. Biopolitics. Psychicsuffering. Subjectivity. Psychoanalysis.

\section{Introdução}

A medicina não é uma ciência pura. Ela faz parte de um sistema histórico, econômico e de poder. (Foucault, 2010c). Assim posto, inferimos que o campo da saude mental, enredado ao projeto da psiquiatria ampliada de medicalização de desvios cotidianos, representa uma estratégia biopolítica hegemônica de gestão dos sofrimentos psíquicos, uma vez que seus fundamentos se associam aos eixos centrais em relação aos quais se articula o conceito foucaultiano de biopolítica, quais sejam: a centralidade da norma e a oposição normalidade-patologia, a apreensão dos fenômenos vitais que caracterizam as populações por estudos quantitativos, a questão do risco e dos dispositivos de segurança a ele associados, o governo das populações como modelo de gestão que invalida o governo de si (Caponi, 2009, 2012a, 2012b).

Procuramos estabelecer, assim, contraposições à associação normalizadora entre sofrimento psíquico e patologia, por meio de uma vertente que nos permitirá pensar o pathos em suas possibilidades de expressão subjetiva, ultrapassando a lógica reducionista 
da visão biomédica, que o captura num viés quantitativo, enquanto fuga da norma.

Referimo-nos aqui à ética em psicanálise. Acreditamos que a mesma sugira um modo diferenciado daquele estabelecido pelo campo da saude mental e da gestão biopolítica a ela associada para pensarmos a relação que a clínica médico psicológica estabelece com o sofrimento psíquico ao entendê-lo como possibilidade constitutiva do sujeito e não como falha e deficiência a ser tratada.

Os discursos e práticas em saude mental promovem uma reconfiguração dos modos de subjetivação em torno do sofrimento psíquico, referente ao domínio ético, na medida em que produzem novos critérios a partir dos quais os indivíduos são levados a valorar suas condutas, deveres, prazeres, sentimentos, enfim, ao conjunto de uma experiência de si.

Neste sentido, acreditamos que o campo da saude mental produz uma mutação na experiência subjetiva porque, quando elabora sua compreensão do sofrimento psíquico, mediante os paradigmas da racionalidade médica, em especial, a prevenção dos riscos e a promoção de saude, inaugura não apenas novas modalidades de intervenção, mas, sobretudo, eleva à condição de objeto clínico, novos quadros ou "figuras". $\mathrm{Ou}$ seja, a saude mental toma sob seus cuidados uma serie de fenômenos, em sua maioria problemáticas de cunho psicossocial, dirigindo sobre eles, um conjunto de intervenções.

De fato, o perímetro de atuação da clínica psicopatológica, antes delimitada a atenção as tradicionais entidades clinicas (neuroses, psicoses), ou seja, aos modos de apreensão da loucura enquanto doença mental, hoje se encontra em expansão. Atualmente, as equipes multiprofissionais que atuam no campo da saude mental desenvolvem uma miscelânea de intervenções, a maioria delas amparadas pelas políticas públicas, em prol da qualidade de vida, por exemplo, de obesos, fumantes, sedentários, idosos, adolescentes em cumprimento de medidas socioeducativas, etc.

Tal contexto, por sua vez, nos permite problematizar a dimensão ética, haja vista a construção de novos formatos de subjetivação, ou seja, de novas possibilidades de reconhecimento de si e de enlaçamento social. Talvez seja essa a contribuição da psicanalise à medicina, haja vista a minimização do sujeito na experiência clínica contemporânea no campo da saude mental. Através dela, apontamos esforços para a construção de um modo diferenciado daquele estabelecido pelo biopoder para pensarmos sobre a nossa relação com o sofrimento psíquico e os modos de atenção clínicos.

\section{Metodologia}

Constituímo-nos enquanto um estudo teórico conceitual orientado pela perspectiva genealógica de Michel Foucault. Deste modo, apreendemos a prática discursiva da psiquiatria ampliada enquanto um dispositivo, ou seja, objeto da descrição genealógica, em que vemos entrelaçados o dito e o não dito, o discursivo e o não discursivo. Quer dizer, uma trama composta de variáveis heterogenias e divergentes entre si, em que a ciência é apenas um dos elementos em relação.

Integrada por um conjunto de princípios metodológicos para a análise das formas do exercício do poder, a genealogia nos oferece um caminho para a análise do saber sobre o sofrimento psíquico, organizado pelo discurso psiquiátrico na cena psicossocial. De fato, não objetivamos analisar a positividade do discurso psiquiátrico, submetendo-o ao crivo da episteme cientifica, e a partir daí, demarcar sua compatibilidade ou incompatibilidade em relação a esta. Pretendemos investigar o aparecimento do saber, que transforma o sofrimento psíquico em norma de subjetivação, a partir de condições de possibilidade que lhe são externas (Machado, 2007).

É precisamente contra os efeitos de poder de um discurso científico 
universalizante, assim como contra seus conteúdos, conceitos e métodos, que uma genealogia não pode se furtar. Toda pesquisa, que tenha como propósito apontar o conteúdo latente, ou seja, os conteúdos disfarçados e deformados, os saberes eruditos e os saberes desqualificados, nos discursos sistematizados e formalizados, deve ser apreendida em termos de uma atividade genealógica. Esta não está, decididamente, interessada em problematizar a possibilidade de inserção de determinados conhecimentos na racionalidade científica e nos critérios por ela requeridos. (Foucault, 2010b).

Diante da questão de ser ou não ser ciência, um trabalho genealógico irá problematizar justamente o oposto, ou seja, a necessidade de cientificizar tais conhecimentos, de alinhá-los a estrutura formal e estrutural da ciência. Faz-se necessário, inclusive, questionar a ambição desmedida pelo poder que o anseio de ser uma ciência traz implícito. Ora, são evidentes os efeitos de poder que a sociedade oferta ao discurso cientifico e é daí que provém a tentativa de vinculação dos saberes à racionalidade cientifica. Contudo, devemos advertir-nos que, na medida em que um determinado saber é elevado ao status de cientificidade, outros saberes são minimizados e marginalizados, incluindo, aqueles provenientes da experiência individual e imediata. E ainda, estabelecem-se a exaltação de determinados sistemas teóricos políticos em detrimentos a outras formas de saber (Foucault, 2010b).

Neste sentido, não mostramos aqui de que discursos o saber psiquiátrico sobre o sofrimento psíquico é efeito ou resultado. Queremos situar o saber psiquiátrico, especialmente a generalização deste na totalidade da existência, como um elemento do dispositivo essencialmente político. Quer dizer, mostrar como ele se manifesta enquanto ferramentas que animam relações de poder. Entendemos que todo conhecimento, incluindo o cientifico, tem sua condição de existência na política. Se tem algo importante na investigação genealógica, é que ela denuncia a impertinência da dicotomia entre ciência e ideologia. Não existe saber neutro. Todo e qualquer saber é político (Machado, 2007).

\section{Resultados e Discussão}

\section{De perto ninguém é normal: sobre a ampliação e generalização da psiquiatria na sociedade}

Conforme as suposições de Ehrenberg (2004), o campo da saúde mental teve participação significativa no aumento da heterogeneidade de problemas tratados $\mathrm{e}$ consequente alargamento do perímetro de atuação da medicina mental que, a partir dos anos 70, deixa de estar vinculada exclusivamente as práticas asilares. A psiquiatria se ampliou, desvinculando-se do modelo hospitalocêntrico, cujo objeto de intervenção era a loucura propriamente dita, apreendida pelo campo da psicopatologia e suas entidades clínicas, para tomar sob seus encargos uma série polimorfa de fenômenos indicativos de sofrimento psíquico.

A segunda metade do séc. XIX inaugurou uma nova percepção da loucura. Delírios, alucinações, melancolias e manias já não são mais os fenômenos primordiais sobre os quais se bordejam o conhecimento e ingerência psiquiátricos. Tal descontinuidade permite a catalogação e classificação de condutas e atitudes vulgares da vida cotidiana enquanto sinais e sintomas de patologias psíquicas passiveis de ações terapêuticas. Estamos diante de um novo espaço de saber e intervenção médicos constituídos e amadurecidos pela patologização do cotidiano que, ao redefinir e valorar a experiência humana em termos médicos, cria novos objetos clínicos (Caponi, 2012a).

Trata-se aí do que nomeamos por psiquiatria ampliada, uma psiquiatria extra e intra asilar, ou seja, uma disciplina que maneja de modo equivalente delírios e tristeza cotidiana. Nesta, pequenos desvios, sofrimentos ou debilidades são tomados por problemas médico psicológicos, não 
exatamente por serem considerados patologias receptoras de intervenções curativas, mas, sobremaneira, por serem capturados como objetos de ações preventivas, próprias de estratégias biopolíticas, haja vista serem significados como fatores de risco que afetam a ordem social (Caponi, 2012a).

Trata-se, enfim, da consolidação de um campo de conhecimento e intervenção nomeado por Foucault (2010b) como medicina do não-patológico, cuja psiquiatria ampliada e as "doenças do homem normal" (Le Blanc, 2007) por ela definida é seu maior representante. Neste sentido, somos atores e telespectadores de uma medicina que, ao produzir doenças da normalidade, dilui a fronteira entre as esferas do normal e patológico, e ainda, naturaliza e medicaliza comportamentos componentes da existência humana.

Deste modo, entendemos por ampliação da psiquiatria o aumento de perímetro discursivo e interventivo de uma disciplina que, outrora dedicada a loucura apreendida enquanto doença mental, hoje se vê debruçada sobre os diferentes dissabores do conjunto da existência humana. Ou melhor, referimo-nos a um conjunto discursivo e estratégico que delega a psiquiatria o saber poder de interrogação e deliberação de condutas e problemáticas eminentemente sociais. É por meio desta conjuntura que acontecimentos triviais como alterações do apetite, disfunções na atividade laboral, dentre outros, passam a ser analisados enquanto indicadores de transtornos psiquiátricos.

Então, tendemos a pensar nossas dificuldades e problemáticas inerentes as relações intra e intersubjetivas em termos médicos e, mais precisamente, psiquiátricos. A impulsividade e descontrole emocional de uma criança, antes problematizados enquanto sintomas referidos a dinâmica familiar em que esta significava suas ações, atualmente é diagnosticado como transtorno disruptivo de desregulação de humor. Mulheres sensíveis aos sintomas da tensão pré menstrual são diagnosticadas pelo mesmo equipamento como portadoras de transtorno disfórico pré menstrual. Alterações de condutas menores como as que caracterizam, por exemplo, o transtorno disruptivo de desregulação de humor passam a ser assim catalogadas para serem prevenidas, evitando sua transformação em patologias mais graves, como o transtorno bipolar. De fato, as intervenções endereçadas as pequenas anormalidades tem como argumento maior a prevenção da cronificação e irreversibilidade das patologias psiquiátricas. Para a multiplicação de transtornos mentais daí reforçada, haja vista qualquer desvio da existência ser apreendido como fator de risco ao desenvolvimento de patologias maiores, teremos explicações biológicas, como deficiência nos neurotransmissores, passíveis de serem restabelecidas por meio de indicação terapêutica medicamentosa (Caponi, 2012a).

Nesta medida, acreditamos que o paradigma da psiquiatria ampliada diz da constituição de um discurso que justifica suas ações e modos de agir pela promoção da iniciativa, ou seja, da autonomia direcionada a todos os indivíduos, sem exceção. Não é à toa que hoje, a saude mental, é considerada um problema de saude publica. E ainda, um elemento de posse fundamental para que um indivíduo qualifique a si como saudável. Com efeito, "o fato de justificar nossas maneiras de ser e nossas maneiras de fazer nos termos da autonomia é o elemento que induz a adotar uma linguagem da vulnerabilidade individual de massa" (Ehrenberg, 2004, p. 3).

\section{A psiquiatria ampliada: uma estratégia biopolítica}

É analisando o nascimento da medicina moderna e das descontinuidades das estratégias de poder que ela engaja, que Foucault (1984) enuncia, pela primeira vez, o conceito de biopolítica. Para ele, a medicina moderna é uma prática social que tem como epicentro determinadas tecnologias do corpo social. Não foram as intervenções médicas sobre os indivíduos apreendidos em sua individualidade, ou seja, uma medicina 
individual e privada, que permitiu a inserção da medicina no campo da ciência. Foi a implantação de uma medicina social, coletiva, sustentada no processo de urbanização, incluindo a produção de força de trabalho, que fez circular o poder político da medicina. Neste, os fenômenos do espaço social, assim como os indivíduos que dele fazem parte, são constantemente esquadrinhados, monitorados e divididos, mediante o estado de saúde, definidor das condições de vida e existência.

Nestes termos, a atividade médica, antes de ser privada, é e sempre será uma ação que visa o social. Dizendo de outro modo, o perímetro de atuação da medicina se constituiu, e este é seu essencial, para além do território privado da doença, na saúde geral da população, em especial, na prevenção de anomalias e promoção do normal. De fato, hoje, sobretudo, todos os domínios da vida individual e coletiva parecem ser capturados pela dimensão médica. Deste modo, as instituições do saber e poder médico tem a função de garantir a sociedade não apenas a vida, mas, precisamente, a vida em boa saúde. De fato,a saúde, a doença e o corpo se transformam nos elementos a partir dos quais irão se organizar a socialização dos indivíduos. Vivemos uma somatocracia, regime que atribui ao estado a tarefa de zelar pela saude dos indivíduos mediante estratégias que incidem sobre os corpos destes (Foucault, 2010c).

Trata-se, enfim, da constituição de um poder sobre a vida. Este, foi possível a partir da intersecção entre duas facetas que guardam seus fundamentos na relação que estabelecem entre si, são elas: a anátomopolítica do corpo humano e a biopolítica da população. A primeira centra sua atenção no corpo como máquina. Incluem-se aí todos os instrumentos e medidas que tem como objetivo a docilização, a maximização de suas funções e aptidões. Referem-se a ela a administração dos corpos possível por um conjunto de táticas constituintes das disciplinas estruturantes em escolas, prisões, hospitais, etc. A segunda, visando gerir matematicamente a vida, centrou-se no corpo espécie e no desenvolvimento de uma gama de intervenções reguladoras sobre os índices de natalidade e mortalidade, saude e adoecimento das populações, longevidade, dentre outros, tomando como suporte a mecânica do ser vivo e seus processos biológicos (Foucault, 1988).

Ora, foram os métodos dedicados ao aprimoramento e a qualificação de aptidões do homem, possibilitadas pelo saber disciplinar, e o controle dos fenômenos populacionais, engendrado pela biopolítica das populações, que fomentaram a qualidade do desempenho dos corpos na atividade de produção e o consequente fortalecimento dos processos econômicos. Com efeito, o investimento na gestão do corpo vivo que o biopoder e a biopolítica encenam, demarcam a inserção dos fenômenos inerentes à vida da espécie humana nos mecanismos de saber poder próprios à política. Tal estrutura de poder propõe uma relação inédita entre biologia e história em que é a vida do ser vivo que possibilita a construção e os destinos da política (Foucault, 1988).

Nessa nova tecnologia de poder, nessa biopolítica, trata-se de apreender os problemas econômicos e políticos mediante a constituição de novos objetos de saber e alvos de controle àquele associado. É neste contexto que se vê delinear-se um conjunto de processos que, lançando mão da medição estatística, debruçam-se sobre uma série de fenômenos - nascimentos, óbitos, fecundidade, reprodução, morbidades, etc. - a fim de suprimir ou retardar as possíveis ameaças que tais fenômenos trazem ao exercício útil da vida (Foucault, 2010b).

Certamente, foi o investimento nestes fenômenos, a partir da segunda metade do séc. XVIII, por essa nova estratégia de poder, que fez entrar em cena, na vida global da população, no seu cotidiano, uma medicina que vai se encarregar não somente da terapêutica de doenças no espaço hospitalar, mas, sobretudo, tomará para si a função maior da medicalização da população mediante os 
preceitos da higiene pública. É a partir daí que surge um conjunto normativo de saberes centralizados destinados a construírem informações educativas sobre os modos de gestão da vida a massa populacional. Como exemplo temos as referências teórico e práticas de como controlar a natalidade, de como exercer a vida reprodutiva, de como evitar a contração de doenças, etc. Percebe-se a amplitude do campo de intervenções da biopolítica que toma sob seus encargos uma gama de eventos universais (velhice) e acidentais (enfermidades), a fim de repelir as consequências de incapacidade ou exclusão do campo produtivo que os mesmos provocam nos indivíduos por eles afetados (Foucault, 2010b).

É em relação a esta variedade de fenômenos que a biopolítica irá constituir seu saber e demarcar a área de intervenção de seu poder. Ora, é justamente aí que se pode encontrar o ineditismo desta nova técnica de poder, que a biopolítica inaugura. Ora, ela, a biopolítica vai construir, não apenas uma rede assistencial para tratar estes fenômenos. Tal já existia. Ela irá desenvolver um conjunto de mecanismos estruturalmente organizados e, por isso, efetivos, que, por conseguir introduzirem-se de modo sutil no cotidiano global da população, alcança seus objetivos com êxito e, o que é mais significativo, sem grande ônus econômico para o Estado (Foucault, 2010b).

Talvez não seja absurdo, portanto, tomar esta transformação de poder que se centra na vida do homem enquanto ser vivo como pano de fundo para compreendermos a importância assumida pela noção de saúde mental nas elaborações científicas, sobretudo, médico psicológicas que inundam os meios político e social. Tal noção parece se situar precisamente no eixo constituinte da tecnologia de poder sobre a vida, na biopolítica. Ora, a saúde mental se refere ao controle populacional mediante intervenções que visam toda a massa social. Basta atentarmos para a proliferação de políticas públicas e pesquisas epidemiológicas que se debruçam sobre a questão.

Posta nestes termos, temos que a psiquiatria ampliada promove a gestão da normalidade, quer dizer, o controle de estilos de vida normais para o exercício e manutenção de sua norma, qual seja, a autonomia. Esta norma é social e não clínica. Trata-se, pois, de uma gestão biopolítica e não de uma terapêutica do sofrimento psíquico. Evidenciase, ainda, um processo contínuo de patologização da normalidade e consequente (des)patologização da clínica que, ao invés de tomar sob seus encargos o fenômeno psicopatológico em si, cria e toma por objeto de intervenção as doenças do homem normal, ou seja, disfunções sociais para as quais os critérios de diferenciação entre o normal e o patológico não são requeridos.

\section{A Ética da Psicanálise como Resistencia a Psiquiatria Ampliada}

A psicanálise, de acordo com as diretrizes estabelecidas pela OMS, entende que a saúde é um direito do homem e que, portanto, as políticas devem se mobilizar para tal. Não obstante, seu engajamento neste campo se dá por outra via. Outros questionamentos, para além dos econômicos e sanitários, são levantados, como por exemplo, o significado de boa saúde, assim como dos fatores dela dependes (Arenas, 2011).

A pluralidade característica da singularidade do homem, expressa em seus devaneios e anormalidades cotidianas, são capturados pelo campo da saúde mental enquanto sintomas deficitários, que põem em risco a demanda totalitária de saúde para todos quando, na verdade, apontam para a relação do homem com a linguagem. E, esta, por certo, está fadada ao equívoco. Evidentemente, é por estarmos atravessados pela linguagem que podemos inferir uma condição de delírio generalizado. Explicando melhor, o sujeito faz uso da linguagem, para assim, bordejar o impossível de significação do real, mediante a construção de significantes singulares que o permitam aportar-se junto ao desejo do Outro. 
Esta configuração envolve uma miscelânea de formações sintomáticas, que transcendem os modos de adaptação social favoráveis ou não (Arenas, 2011).

Neste sentido, inferimos que a junção de esforços em prol da consolidação da igualdade tem como efeito a segregação acentuada, pois, em última instância, no mais íntimo do ser, habita o estranho. $O$ sujeito ocupa uma posição de extraterritorialidade em relação a si próprio. É o que revela o delírio psicótico: o sinistro e estrangeiro de nós mesmos. Contudo, o destino destes na cultura é a segregação e a exclusão do laço social, mesmo em épocas de desconstrução do modelo antimanicomial. Assim posto, indagamo-nos: onde posicionar aquilo que se exclui da norma para todos? Talvez a política psicanalítica de pensar o comum sem a exclusão da diversidade singular, fora do campo identificatório e imaginário, aponte-nos as respostas. Apostamos que a intersecção entre o dispositivo analítico e as políticas públicas de saúde podem sustentar-se na orientação não segregativa do primeiro. $\mathrm{Na}$ construção, pois, de uma "perspectiva de la salud para todos como algo que nos es común, pero no sin la locura de cada uno que incluyalo singular." (Arenas, 2011, p. 30).

O problema central em saúde mental circula ao redor de capacidades adaptativas, referentes a aportes emocionais, que permitam a cada um entrar, sair e retornar. São, inclusive, os experts em saude mental que autorizam e, porque não dizer, legislam e fiscalizam tais atos, devendo intervir para a reintegração à comunidade social, quando estas capacidades são enfraquecidas. Neste sentido, a decisão sobre a responsabilidade do indivíduo, quer dizer, de gestão de si mesmo, constitui-se como critério fundamental em saúde mental. O problema é que a doença mental, ou como queiram designar, as deficiências, estão em nós de saída. Há, pois, uma perturbação estrutural na tríade biopsicossocial. $\mathrm{O}$ pensamento inconsciente não é da ordem do mental e deve ser distinguido, ainda, da definição de saude da
OMS, afinal, ele não se assimila ao completo bem estar. É de uma (des)harmonia que ele vem nos informar (Miller, 2011).

Podemos inferir, deste modo, que, nesta definição de saúde mental, a posição ético política da psicanalise não se acomoda e, por isso, posta nestes termos, o psicanalista não é um trabalhador da saúde mental. Embora interlocuções possam ser travadas, deve-se reconhecer, para tanto, que, em psicanalise, não se trata de saúde mental em termos de normatização de condutas. Insistamos, o psicanalista não promove saúde mental. De fato, quando as coisas caminham bem no processo de escuta analítica, ele próprio, o analista, sai de cena (Miller, 2011).

Desta maneira, discutir os destinos da leitura psicanalítica sobre o campo da saúde mental implica considerar que, se a psicanálise é definida como método de investigação dos processos inconscientes então, não há outro meio de apreender os problemas levantados senão pelos questionamentos que o prisma do inconsciente vem suscitar.

Para tanto, comecemos por definir o saber agenciado por Freud, assim como a racionalidade que este comporta. Conforme Fuks (2007), a psicanálise inaugurou uma forma radical inédita de refletir sobre a cultura, fato que a fez destituir a divisão clássica entre psicologia social e psicologia individual. A escuta clínica ensina que a experiência subjetiva é atravessada pela referência do sujeito ao outro semelhante, assim como à linguagem, que o determina simbolicamente. Freud elaborou uma teoria sobre cultura totalmente articulada às bases do saber psicanalítico, levando as consequências do inconsciente até o fim, na medida em que estendeu seus ensinamentos para além dos sintomas neuróticos, abarcando o mal estar presente na convivência humana.

Deste modo, o uso da psicanálise enquanto dispositivo de saber de entendimento dos fenômenos sociais deve submeter-se a exigência de vigilância ao fundamento freudiano, segundo o qual as leis que regem o 
sujeito do inconsciente são as mesmas que regem e fundam a cultura.

Vale destacar, contudo, que o inconsciente não é o acesso ao que está sempre ali. Ele próprio é faltoso. Tal característica lhe garante outra especificidade epistêmica, qual seja, o interesse do sujeito por ele mesmo. Enquanto a ciência tradicional propõe uma separação entre sujeito e objeto, visando a fidedignidade do conhecimento, Freud demonstra que o traço próprio a seu objeto, a falta, está na própria constituição do sujeito. $\mathrm{O}$ inconsciente nos confronta com esta misteriosa realidade e a teoria deve deixar-se impor a esta lei, própria de seu objeto.

Isso constitui uma posição de racionalidade, que deve ser considerada também na problemática da saude. Assoun (1996) indica, inclusive, ser errado definir a psicanalise como uma visão de mundo pautada no sexualismo, ou seja, um pansexualismo. Freud, em vez de tomar a sexualidade como fato, tornou-a um problema. A sexualidade é problematizada, assim, enquanto falta destotalizante que comporta a psique com sua inconsistência. Ela propicia à metapsicologia, arcabouço teórico da psicanalise por excelência, a revelação e o reconhecimento daquilo que se furta ao conhecimento.

A clínica mostra o sujeito exposto ao interdito. A metapsicologia é, justamente, a construção do saber dessa relação do sujeito com o interdito. Algo só passa a ser pensado enquanto uma problemática metapsicológica quando aparece primeiramente enquanto questionamento clínico. A metapsicologia é uma pós escritura de algo que se anunciou na escuta clínica neurótica. Neste sentido, pensar o campo da saude mental a partir de uma teoria psicanalítica, ou seja, da metapsicologia, implica considerar que é a partir da escuta analítica e sua produção que se pode efetuar uma leitura do social. Dito de outro modo, um fenômeno social deve ser apreendido, pois, pela lógica do desejo, enquanto destino pulsional. Isso significa que o que interessa não é o fenômeno em sua literalidade, mas naquilo que ele comporta da singularidade que o agencia.

Segundo Assoun (1996), então, quando Freud insiste nas resistências á psicanalise, significa que ela traz em sua mensagem algo que desorganiza a estrutura humana, colocando-a em contradição consigo mesma, ao apresentar o irredutível encontro do sujeito com a falta. $\mathrm{O}$ destinatário da verdade analítica, a de um não sabido, do qual a sexualidade é sua face, daí falar-se numa sexualidade infantil, só pode ser o sujeito do inconsciente, um a um, por sua conta.

Embora o sujeito não seja uma categoria metapsicologia, é ele quem organiza a experiência do inconsciente, o sujeito da cena primitiva, do encontro sempre faltoso com o Outro. O processo de cisão do sujeito, operacionalizada pela representação da castração, obriga a pensar numa verdade inédita, contraria a racionalidade científica, tornando impossível qualquer síntese do eu. O sujeito se estrutura numa hiância estrutural do saber, na qual o sintoma nasce justamente, não de um mal entendido, mas pelo entendimento da clivagem lógica necessária à constituição do sujeito. O neurótico, antes de ser um doente, é portador de uma exigência simbólica, estruturante do próprio saber clinico. Ora, "o próprio sujeito se apresenta como uma verdadeira pequena teoria do conhecimento encarnada, já que, no trabalho do inconsciente, é esta cisão que ele reproduz como sua "história", a de sua divisão" (Assoun, 1996, p.34).

O sujeito não é o inconsciente, mas somente pode ser pensado a partir deste campo. É verdade que a expressão sujeito do inconsciente não está em Freud. Lacan a utiliza para demarcar a posição do inconsciente na psicanalise. Tal expressão não identifica o sujeito. Se a tomássemos literalmente, teríamos que tomar o inconsciente como uma instância, uma substância, propósito jamais adotado por Lacan. Este não buscou identificar sujeito e inconsciente. Sujeito do inconsciente nos 
informa que o sujeito não tem identidade, uma vez que o inconsciente é o não realizado. Ao que concerne ao retorno de Lacan a Freud, portanto, compreende-se que a possibilidade de interlocução entre psicanalise e saude mental está entrelaçada a concepção do sujeito do inconsciente, tal qual proposta por ele.

Conforme Fink (1998), o conceito de sujeito é uma suposição necessária para Lacan. Assim, o sujeito lacaniano não é de modo algum equivalente a noção de "indivíduo" ou sujeito consciente próprio da filosofia. O sujeito não é o "eu". A este está reservado o lugar das fixações narcísicas agenciadas pelo inconsciente. Especificando melhor, o sujeito lacaniano não se reduz ao eu consciente ou, ainda, ao sujeito do enunciado, que emite frases de autonomia tais como "eu penso", "eu acho", etc. Tais enunciados ou conjunto de palavras são entendidos como significantes ou, como Lacan os nomeava, "tesouros", pelo qual o sujeito advém. Aquilo que é dito no discurso consciente tende a deparar-se com outro discurso que o nega. É esta ambivalência própria da palavra que nos permite ver o sujeito. Daí a importância dada às formações do inconsciente, sonhos, lapsos, atos falhos, etc., que comparecem como furos no discurso.

Ao sujeito lacaniano está resguardado o lugar da transitoriedade. Ele desponta e desaparece quase que instantaneamente. Nas formações do inconsciente uma intenção estranha rouba a cena do discurso consciente, fazendo-o vacilar. É interessante dizer que esta intencionalidade do inconsciente fez Freud associá-lo a uma instancia com uma subjetividade e intenção próprias. Lacan, por sua vez, não considera o inconsciente enquanto uma instância, mas, prioritariamente, outro discurso separado da consciência, e ainda, o discurso do Outro.

O sujeito lacaniano é, portanto, dividido, fendido, aquilo que se desdobra para além da atividade subjetiva consciente, de acesso voluntário. O sujeito lacaniano é dividido entre $o$ eu/consciente e $o$ inconsciente, entre um sentido inevitavelmente falso de eu e um funcionamento automático próprio da linguagem, evidenciado pelo desenrolar da cadeia significante. Lacan matemiza sua suposição de sujeito por $\mathrm{S}$ maiúsculo barrado, indicando assim a disjunção radical entre as duas partes componentes do falante. Essa clivagem (spaltung) entre um falso eu e um inconsciente nos informa da inserção/alienação da criança ao mundo da linguagem. É um trauma de cada novo ser falante. A divisão é a condição de possibilidade do sujeito.

A partir desta definição de sujeito do inconsciente, podemos pensar as relações entre a ciência, campo onde se situa o discurso da saude mental, e a psicanálise. Lacan (2008a), indaga-se sobre se a psicanálise seria uma ciência e logo responde que a questão precisa ser subvertida. Deve-se questionar, antes, se a ciência teria condições de abarcar a psicanalise. Ora, é a psicanalise que nos permite esclarecer sobre o que deveria ser uma ciência. Tal é assim porque a psicanalise não se constitui como uma pesquisa, pelo menos no modelo científico padrão, uma vez que ela não se concentra na busca - do bem estar, do conceito de saude, etc.

Fink (1998) alerta para as consequências de se querer regulamentar a prática psicanalítica, pela promoção de uma padronização, em nome da ciência. Tal movimento poria um entrave ao estatuto do saber psicanalítico, assim como da natureza da verdade que ela sanciona em sua experiência. Ora, embora a psicanalise tenha sido possibilitada, epistemologicamente falando, pelo advento do sujeito cartesiano, próprio a ciência moderna, o estatuto da psicanalise não coincide nem coincidirá com a natureza da ciência. A psicanalise, assim como o deveria ser a verdadeira ciência (pelo menos como Lacan a compreendia), cria o novo, introduz o real. Lacan (2008a) entende a psicanálise como sendo uma ciência conjectural. Assim, poderíamos apontar o limite entre ciência e psicanalise no entendimento da verdade que cada uma sustenta. Enquanto a ciência exclui a 
verdade, a psicanalise a toma como ponto fundamental.

Mas então, de que verdade trata a psicanálise? $\mathrm{Na}$ tentativa de dar conta deste questionamento, Cancina (2008) responde que, em psicanálise, o que está em jogo é a verdade do sujeito, buscada não na investigação objetiva, ancorada no método habitual, mas, naquilo que lhe causa, ou seja, em sua divisão estrutural, tributo indispensável para todo ser falante atravessado pela linguagem.

A questão da verdade em Freud foi abordada numa perspectiva histórica (fantasística). Ele nos informa da impossibilidade de objetivar a verdade do sujeito. Lacan avança e diz que há aí uma convocação ao sujeito. Ora, na análise o sujeito se depara com o fato de que sua verdade foi uma criação. Assim, quando Lacan (1998) diz "je parle laveritê" (eu falo a verdade) quer com isso anunciar o " $j e$ " (eu) da enunciação, daquele que porta sua verdade, na medida em que esta precisa ser dita por alguém. Não se pode cair no engodo de pensar a verdade como externa ao sujeito que se questiona sobre sua verdade. Especificando melhor: não há uma verdade racional sobre o sujeito passível de ser apreendida pelo discurso cientifico em saude. A verdade é do sujeito, este a porta!

Cancina (2008) informa que além da relação mantida com o ato de desocultar, a verdade, em psicanalise, se relaciona também com o ocultar. A neurose, figura ambígua da verdade, é um exemplo. O sintoma neurótico diz, através daquilo que falha na linguagem, do l'insu (não dar-se conta), de um saber que não se sabe. Entretanto, ele também comparece como aquilo que tampona a divisão - spaltung - indicativa da verdade do sujeito. Pode-se dizer que as formações do inconsciente revelam uma verdade que se oculta ao mesmo tempo que se mostra, ou seja, desocultamento que oculta.

O inconsciente é um saber que não se sabe. Portanto, a psicanálise deve informar ao campo da saude mental a verdade como não toda. Com isso, transmite-se algo do real, de sua impossibilidade. É preciso demarcar que em psicanalise real significa o registro impassível de significação, inapreensível pelo simbólico. As construções em análise demonstradas por Freud nos falam desse real ao qual podemos acessar "um pouco", indicando o limite do saber.

As tentativas de conceituação em saude mental devem ser tensionadas por esta perspectiva. Lacan radicaliza a concepção de verdade enquanto uma ficção. $O$ real não é consistente, refere-se a uma ex-sistência. Embora o conceito capture, ele não dá conta totalmente do real. O real é assim, o fracasso do conceito como ideia de apreensão. Pode-se equiparar o conceito a pulsão. Ambos rodeiam um objeto sem jamais captura-lo por completo. Assim, a estrutura do sujeito do conhecimento é igual a estrutura do sujeito da psicanálise, ou seja, o sujeito da ciência. A estrutura do sujeito do conceito é a mesma da pulsão e do circuito que esta percorre repetidamente na busca do objeto para sempre perdido, uma vez que nunca existiu (Cancina, 2008).

Quando Lacan (2008a) diz que a psicanalise trabalha com a verdade enquanto causa do sujeito, deseja insistir no fato radical de que tal causa não obedece a leis apreensíveis pelo conhecimento cientifico, seja qual for o construto teórico simbólico utilizado. Este tipo de assimilação é inadmissível nos dias de hoje quando o confronto com a castração é impossível de sustentar, inclusive pelo discurso do capitalista.

Delimitar as consequências éticas da produção de saber psicanalítico que sirvam de contribuição ao campo da psiquiatria ampliada implica retomar, conforme Lins (1996), a subversão feita por Freud aos saberes de sua época pela fundação de um saber que não se sabe, que não se esgota com o conhecimento, uma vez que não cessa de se inscrever por um real, renegados pela ciência. Assim, o saber concernente ao psicanalista em suas 
possibilidades de interlocução com outros sabres, é o inconsciente, esse saber do qual não sabemos, l'insu. É importante aqui remarcar que isso que não se sabe, e a concepção de interpretação psicanalítica deve ser capturada por isso, não se refere a uma memória perdida que o saber psicanalítico relembrará. O recalque não será ultrapassado pela via do significante. Tal nos informa de que algo escapa ao simbólico, algo de nós enquanto sujeitos falantes e, pois, do nosso acesso a este saber.

Com efeito, "a lógica da psicanálise é a lógica do não todo, do não absoluto, do saber não todo, do um da série e não do um da totalidade" (Lins, 1996, p. 164). Freud já havia se confrontado com o impossível quando teorizou sobre o que nomeou umbigo do sonho. Especificando melhor, a posição ética da psicanalise é de desvelar tanto na clínica como na cultura, a incompletude fundamental do ser falante contestando seus véus enganadores. Somente assim o sujeito pode vir a responsabilizar-se por si. É confrontando a falta enquanto causa que se pode produzir algo. Ora, só há causa naquilo que falta. É, pois, no confronto com a impossibilidade que há a possibilidade de fazer algo, transmitir algo.

A proposta de interlocução entre psicanálise e saúde mental não visa a utilidade. Propõe o encontro com o real como condição para o advento do sujeito faltoso. Ora, "Lacan vem a justo título nos advertir que a Ética vai encontrar suas balizas na relação do homem com o real. Seria enganoso supormos que toda explicação ética devesse portar sobre o domínio do ideal (...)" (Lins, 1996, p. 166). É o confronto com a impossibilidade, causa do sujeito, que se quer saber, saber mais... mais ainda. Dizer de mil formas que nem tudo se sabe por que nem tudo o saber alcança. É o não todo que, ao invés de nos petrificar, convoca-nos a desejar saber dele, saber mais daquilo eu não se pode saber. "Fazer um saber sobre o não saber, eis o nosso saber." (p. 169).
Se a ética da psicanálise se centra na ética do desejo, e por isso se distancia da preocupação de adaptar o homem aos ideais de saúde, então, também se afasta da necessidade de dar respostas às demandas sociais. Tal conduta, vale destacar, produziria "interpretações selvagens" do social que, por sua vez, poriam em cheque a causa da psicanálise.

A partir deste posicionamento, apostamos, então, com Ventura (2012), que talvez seja oportuno pensar a psicanálise hoje enquanto um discurso contemporâneo inscrito na tradição do cuidado de si, conforme indicações foucaultianas. Embora Foucault (2006a; 2010a) tenha destacado os efeitos de sujeição das relações de saber poder na psicanálise, acreditamos que a psicanalise faz barra as formas de normatização, haja vista ofertar espaços de construção de relações de si consigo e com o outro que apontam para possibilidades contrarias as prescrições normativas impressas no bem estar biopsicossocial. ia, inclusive, constitui-se como espaço de resistência.

Embora as referências à psicanálise, constituídas, em sua maioria, por observações críticas, sejam frequentes no texto foucaultiano, o mesmo reconhece que o valor de Freud ao abrir-se a dimensão histórica da existência na importância que deu a significação. Se por vezes as perspectivas naturalistas, evolucionistas, metafisicas e moralistas possam por vezes se fazer presentes na história da psicanalise, seja na teoria das pulsões ou na concepção da enfermidade como regressão, ela conseguiu superar tudo isso. Afinal, foi Freud quem revolucionou a psicologia. Fez da análise causal uma gênese de significações, deu ênfase ao aspecto histórico em detrimento ao aspecto evolutivo e apontou a necessidade de analisar a cultura ao invés da natureza (Castro, 2016).

Por conseguinte, é a interlocução estabelecida por Foucault com a Literatura, que o possibilita apontar a figura de Freud como responsável pela exaltação da linguagem 
da loucura por si mesma, deixando de ser blasfêmia ou portadora de significação intolerante. De fato, com Freud, "a palavra da loucura aparece como uma palavra que se envolve sobre si mesma e diz, por debaixo do que diz, outra coisa, da qual ela é, ao mesmo tempo, o único código possível" (Castro, 2016, p. 181).

Deste modo, a psicanálise freudiana, sobretudo com Lacan, retomou o interesse sobre o problema das relações entre sujeito e verdade, mostrando a complexidade do sujeito $\mathrm{e}$, por isso mesmo, o engodo quando de sua redução da superfície do pronome "eu". Ainda segundo Foucault, é Lacan quem formaliza claramente algo que Freud já havia apontado em seus escritos. Referimo-nos aqui a ideia segundo a qual o sujeito não é originário. Ao contrário, possui uma história, uma gênese que deve ser buscada nas estruturas de linguagem presente na fala dos sintomas das neuroses (Castro, 2016).

Isso posto, pensamos ser possível encontrar, nas próprias questões endereçadas a Freud pelo pensamento foucaultiano, elementos que possam situar a psicanalise como pratica de transformação de si, alheia aos modos de vida normatizado e submisso. Os estudos de Foucault (2006b) sobre o cuidado de si, mediante o retorno a antiguidade greco-romana, aponta-nos o caminho:

(...) se podemos reconhecer uma falsa ciência pela sua estrutura de espiritualidade (isto é evidente, todos os cientistas o sabem), não se deve esquecer que, em formas de saber que não constituem precisamente ciências, e que não devemos assimilar à estrutura própria da ciência, reencontramos, de maneira muito forte e muito nítida, alguns elementos ao menos, algumas exigências da espiritualidade. Dispensável, por certo, traçar-lhes um desenho: de imediato reconhecemos uma forma de saber como o marxismo ou a psicanálise. Assimilá-los à religião é, evidentemente, total engano. Isto não faz nenhum sentido e nada acrescenta. Em contrapartida, se considerarmos um e outra, sabemos bem que, por razões totalmente diferentes, mas com efeitos relativamente homólogos, no marxismo como na psicanálise, o problema a respeito do que se passa com o ser do sujeito (do que deve ser o ser do sujeito para que ele tenha acesso à verdade) e a consequente questão acerca do que pode ser transformado no sujeito pelo fato de ter acesso à verdade, estas duas questões repito, absolutamente características da espiritualidade, serão por nós reencontradas no cerne mesmo destes saberes ou, em todo caso, de ponta a ponta em ambos (Foucault, 2006b/1982, p. 39).

Aí está posta a possibilidade de enredar a psicanálise ao cuidado de si. Certamente, a psicanálise nem pleiteia o status de ciência, nem propõe a submissão dos sujeitos ao governo normatizador, ideário estabelecido pelos dispositivos de saber-poder. Numa posição refrataria, inclusive, constitui-se como espaço de resistência. De fato, como Foucault (1995) afirma, onde há poder há, igualmente, liberdade e luta. Lembremos que o poder só se exerce sobre homens livres.

É na aposta em uma relação consigo como alternativa as estratégias disciplinares e do biopoder, que Foucault retoma a antiguidade grecoromana e a noção por esta agenciada de cuidado de si, menos em nome de um retorno nostálgico do que da possibilidade de construir novos modos de vida. Neste sentido, a noção de cuidado de si diz respeito a um conjunto de práticas - não obrigatórias e não punitivas - que tem como objetivo a mudança de atitude em relação a si pelas ações de atenção, ocupação, apreensão e cultivo de si mesmos, para se ter acesso a verdade singular de cada um (Ventura, 2012). 
Pensar, portanto, a psicanálise, como cuidado de si, implica articulá-la em sua dimensão ética. De fato, supomos que é pela via da ética que a psicanálise pode estabelecer uma interlocução com a medicina de modo a tensionar a demanda totalitária por saúde e bem estar, reforçada pelos discursos e destinos biopolíticos do sofrimento psíquico na atualidade. De fato, faz-se necessário reintroduzir a subjetividade no campo da prática médica, em especial na percepção desta sobre o sofrimento psíquico (Clavreul, 1983; Benoit, 1989; Gori e Del Volgo, 2009; Gaspard, 2012).

Não podemos negar os impasses subjetivos, éticos e políticos em situar a saúde como bem de consumo, passível de ser reivindicada e consumida, numa cultura que transforma o paciente em usuário, esclarecido e de direito, dos cuidados médicos, sem acolhê-lo em sua condição de aflição, e, ainda, privando-o de seu valor subjetivo (cuidado de si). Um destes impasses é a instrumentalização da vida psíquica, graças a inserção do modelo higienista, que desfaz o laço entre singularidade e sofrimento psíquico, através da decodificação precoce de comportamentos pela expertise cientifica.

De fato a tecnocientificização do sofrimento tem como efeito o desaparecimento da dimensão ética. Há mutações nos campos valorativos e simbólicos relacionados ao adoecimento, haja vista o dizer do doente ser apagado em detrimento do dito da doença. Explicando melhor, o discurso médico, esforçado em excluir de seu domínio os elementos intra e intersubjetivos, em prol de uma gestão do ser vivo, desqualifica os dramas imaginários, as determinações simbólicas e a finalidade ética do sofrimento envolvidos no cuidado e na doença. Não é absurdo inferirmos que atualmente, o doente é o porta voz dos signos da doença, intermediário entre $\mathrm{o}$ médico e a patologia (Gori e Del Volgo, 2009).

A captura do sofrimento pela lente racionalista da patologia, faz sobrar um resto e, é sobre este resto que a psicanálise se debruça. Não esqueçamos que os saberes nascem dos pontos cegos de outros saberes. Foi assim com Freud. Seu inédito somente foi possível diante daquilo que se furtou ao conhecimento da racionalidade cientifica anátomoclínica. Foi justamente com isso que ele trabalhou, com aquilo que não se encaixava no discurso da ciência: o sujeito. A medicina alcançou o status de ciência abdicando de sua função ética enredada ao sofrimento que lhe é demandado cuidados. Todavia, "cette médecine ratioennelle et efficace ne serait pas morale si elle ne trouvait pas, d'une manière ou d'une autre, l'occasion d'accueillir le retour du sujetau sein de ses pratiques et de leur théorisation" (Gori e Del Volgo, 2009, p. 65).

A objetivação do sujeito produz o esquecimento do ser, quer dizer, uma amnésia do seu souci de soi. Com efeito, a medicina procede mais da ciência de seu tempo que da arte terapêutica de sua clínica. Na psicanálise, numa via oposta, o acesso à verdade transforma a posição subjetiva, Tal pode contribuir com a restituição da dimensão ética no discurso médico.

Com efeito, é a partir do modo pelo qual o médico responde a demanda do doente onde se localiza a possibilidade de uma posição propriamente ética. Deste modo, o recurso a ética pode fazer retornar o humano ao centro da terapêutica. Esta, não esqueçamos, se confronta com o caráter essencialmente dialógico, da palavra e da linguagem. E ainda, vê-se atravessada pelo sofrimento irredutível a doença, convocando o julgamento médico, que é irredutível a protocolos técnico-científicos. Contudo, a experimentação não abarca a experiência clínica, pois, o diálogo que em seu espaço é estabelecido excede ao dito normativo da ciência (Gori e Del Volgo, 2009).

\section{Considerações Finais}

Acreditamos ser entorno da ética que o campo da suade mental e a psicanálise podem dialogar, não reduzindo esse encontro a 
análise de técnicas. Com efeito, a prática clínica não pode reduzir o homem a um indivíduo psicológico que, na posição de consumidor esclarecido, consome o serviço de saúde. Precisamos, então, reintegrar ao conhecimento em saúde mental uma dimensão ética, de modo que a naturalização do homem pelas insígnias matemáticas não apaguem sua dimensão simbólica, sua função significante. De fato, é nesse ponto limite, em que a medicina não extrai da ciência uma moral para sua conduta terapêutica - a ciência não abarca o todo da doença - que a psicanálise pode ofertar sua contribuição. Afinal, ocupar uma posição de responsabilidade por si não se reduz a condução de uma vida conforme diretrizes morais, incluindo aí, sobremaneira, os estilos de vida saudáveis do discurso biomédico. Numa visada contraria, implica o ato de valorar a vida, que não apaga os conflitos e hiatos que a compõe (Gori e Del Volgo, 2009).

Foi o reconhecimento de Freud da irredutibilidade do fator psíquico ao ato médico que sustentou a inquietante familiaridade entre psiquiatria, psicologia e psicanalise. Ora, antes da tentativa de homogeneização e consenso em psicopatologia pelo DSM, estas disciplinas, apesar de variáveis conceituais e metodológicas, problematizavam a psicopatologia por outras perspectivas como o inconsciente, por exemplo, explorado pela psicanálise. Dito de outro modo, apesar da miscelânea de abordagens em psicopatologia, elas tinham em comum os seguintes aspectos: 1) a doença não se reduz ao comportamento e; 2) o louco expressa o sofrimento ontológico que não lhe é exclusivo. Tal está para além da clivagem clássica entre causalidade orgânica ou psíquica do sofrimento psíquico e da loucura.

Conforme Dunker (2011), é necessário informar que Freud, ao afastar a psicopatologia dos aportes moral, religioso e educativo, concebeu o sintoma psíquico não como o desvio ou ruptura de um estado anterior, circunscritos no ideal de um corpo saudável e/ou infância feliz ao qual se pode retornar pela prática e da qual se deve partir teoricamente. Ora, a teoria psicanalítica não é deduzida do funcionamento psíquico normal $a ̀$ priori. A descoberta do inconsciente por Freud, a partir da escuta ao discurso das histéricas, vem justamente apontar para o desvio como critério do método psicanalítico.

A psicanálise constrói seu conhecimento em psicopatologia ancorada na concepção de sujeito por ela forjada em relação direta com a linguagem. Diferentemente da racionalidade psiquiátrica, cuja ética se funda na ciência, a psicanálise funda sua ética no sujeito. Lacan (2008) diz que embora o sujeito da psicanálise seja o mesmo sujeito da ciência, esta última, a ciência, abdica um dado fundamental do sujeito, a divisão, de onde a psicanálise parte em suas elaborações.

Nesta perspectiva, o sofrimento, mal estar e o sintoma adquirem caráter específico em psicanálise. Para além de uma significação negativa, em que a eliminação é a meta, estes ganham uma indeterminação positiva que informam de um sujeito dividido e as voltas com seu desejo, e, portanto, com sua ética, num movimento constante de se dizer de modo sempre faltoso, na medida em que se está sempre em torno de um real, registro lacaniano que aponta o impossível, o não saber (Albuquerque, 2015).

A leitura de Lacan (2010) sobre as psicoses oferece subsídios para pensar o sofrimento psíquico para além da deficiência, mas como algo que diz de uma diferença que informa sobre como a linguagem é estruturada na constituição subjetiva. Com efeito, diferença em Lacan não é déficit de ordem fenomenológico cultural, mas se constitui na e pela linguagem em suas formas de estruturação, ou seja, nos modos possíveis de relação entre significado e significante. Subvertendo concepções psicológicas e psicogenéticas para as quais o fenômeno psicopatológico deve ser explicado como anomalias da personalidade de evidente ou 
suposto fundamento orgânico, Lacan infere um sentido à fenomenologia da psicose, por exemplo, mas este não se refere a uma compreensão no sentido de buscar a causa e/ou evento psicológico, social ou cultural que a desencadeou como se uma personalidade sadia tivesse sido alterada. Ora, a psicogênese ou busca pelo sentido nos diz de uma busca pelo ideal que se liga mais uma apreensão imaginária do quadro psicopatológico. $\mathrm{Ou}$ melhor, "o grande segredo da psicanálise é que não há psicogênese" (Lacan, 2010, p. 16).

Hoje, contudo, a restauração da psiquiatria pelo registro médico faz-nos confrontar com uma das fases mais reacionárias da história da loucura. As classificações pseudocientíficas do DSM transformam o sofrimento psíquico em desordem. É isso que está em jogo no transtorno mental: uma falha. Trata-se da redução da patologia mental a patologia médica, enfim do abandono de perspectiva dinâmica do psiquismo em psiquiatria. Nestes termos, o sujeito se transforma em consumidor de psicotrópicos e usuário de métodos de reeducação e adestramento que ensinam a governar sua vida da maneira que o convém, expropriado de seu sofrimento psíquico e social. "Il se trouve exposé à la fármacovigilance de praticiens qui ont trouvéle moyen de se désculper de leur implication dans la rencontre clinique avecla folie et las ouffrance" (Gori e Del Volgo, 2009, p. 291).

Complementando, vivemos numa hierarquia em que a pesquisa prevalece sobre a clínica, que se realiza atualmente reduzida claramente a uma tecnologia geral do corpo social. Neste sentido, os clínicos se reduzem a "intermediários quase automáticos entre a indústria farmacêutica e a demanda do cliente, quer dizer, em simples distribuidores de medicamentos e medicação" (Foucault, 2010c, p. 191).

Retomando o mito do totem, mito da ordem primeva, articulado por Freud (1996/1913), a partir de sua escuta clínica, para problematizar a origem da cultura e do laço social, inferimos que este informa do lugar vazio que o pai morto vem representar. Espaço vazio, vale sublinhar, que sustenta a cultura e o laço social. É precisamente essa a função do mito: dar conta da impossibilidade de dizer o real da origem. As religiões monoteístas guardam seu progresso porque uma outra relação com o real se cria, na medida em que a figura do Deus está sempre fora. Ora, é o vazio deixado pelo assassinato do pai que cria o laço social, o simbólico, porque gera culpa. É a morte de Cristo que sustenta o cristianismo. Com efeito, o laço precisa de um lugar vazio para ser.

Em contrapartida, na modernidade, o fato de a medicina ocupar o lugar de mestre antes ocupado pelo totemismo, faz com que a lei simbólica, sustentada pelo espaço vazio, ceda lugar à lei normativa. Tudo hoje é passível de legislação. Os tabus contemporâneos são fundamentalmente biomédicos - a gula circula do pecado para a obesidade como doença crônica, por exemplo. Isso tem seus efeitos. Os discursos imanentes da medicina não fazem referência a um lugar vazio transcendente, pelo contrário, o tampona com ideologias que ela mesma fabrica (reducionismos do homem genético, neuronal).

Neste sentido, a saúde mental, ancorada na expertise científica, funciona como guia moral em favor de uma moral do progresso que, fazendo retornar a ideologia comtiana de ordem e progresso, postula que do conhecimento científico pode se deduzir uma moral da exatidão.

Enfim, a leitura do ethos de uma cultura pode ser feita a partir das representações sociais e cientificas da doença e do cuidado. O valor de uma cultura está impresso nos modos pelos quais ela trata seus loucos, suas crianças e seus doentes. De fato, o cuidado (soin) não diz especificamente do ato médico, mas sim, de uma terapêutica. Esta, por sua vez, anuncia as práticas de si em que o humano é reconhecido como resto irredutível a qualquer formulação racional ou objetiva. 
Assim, faz-se necessário conjugar conhecimento e ética quando se trata do homem doente. Numa via oposta a medicalização da existência, que transforma a vida em doença, reconhecemos no indivíduo atravessado pelo pathos o território das possibilidades de uma vida.

Por conseguinte, a psicanálise não pode se furtar a uma discussão ética, afinal, sua experiência se confronta a problemas morais propriamente ditos, referentes ao universo da falta, no sentido mesmo da infração moral e à dimensão mortífera que ela engaja. Ora, a psicanalise lida com a "atração da falta". Entretanto, essa falta não pode ser significada como o não cumprimento de uma regra. Neste sentido, nem a falta na origem da cultura colocada por Freud no mito do assassinato do pai nem a falta relacionada a pulsão de morte e sua dialética, abarcam a totalidade da importância da dimensão ética no texto freudiano. Aliás, o que tanto o mito da horda como a pulsão de morte nos ensina é que a ética decididamente não se vincula ao sentimento de obrigação. A experiência moral, no sentido de sanção, não reduz-se as relações entre homem e lei. Ela, por colocar o sujeito numa relação com sua própria ação, produz um ideal de conduta a partir do qual tenta se referir (Lacan, 2008b).

Tudo isto está para além de uma reflexão moralista, o que não significa dizer que esta dimensão ocupa uma posição secundaria em suas articulações. Aliás, é inclusive a psicanalise que sublinha a onipresença do sentimento de culpa no sentimento de obrigação. Contudo, a psicanálise é uma experiência que encontra seu fundamento na fecundidade do desejo como tal, sendo aí onde se enraíza a gênese da moral em Freud e, justamente por isso, ponto de partida para o trabalho psicanalítico em saude mental, afinal, são os destinos do desejo que vemos desenhar-se as possibilidade múltiplas de posicionamentos morais (Lacan, 2008b).
Nesta perspectiva, qualquer tentativa de conformação a um ideal tende ao fracasso. Basta retomarmos o caráter perverso polimorfo da sexualidade infantil para encontrarmos as origens paradoxais do desejo. Com efeito, é em torno da pulsão parcial em que se situa a função do desejo e sua notável e profunda variedade. De forma alguma este alerta freudiano deve fomentar percepções moralistas que localizam na intervenção analítica a possibilidade de domar o gozo perverso fazendo com que os elementos paradoxais do desejo convirjam em direção a um fim harmonioso ou feliz, apaziguando o sentimento de culpa do paciente (Lacan, 2008b).

Em o Mal-estar na Civilização (1929/1996), após a elaboração da segunda tópica, para a qual a pulsão de morte vem ocupar uma posição central, quando Freud situa o mal estar além do homem, nas relações deste com o logos, informa que a experiência moral não se restringe ao ato de resignação diante de algo perdido. Definitivamente, não se trata de acomodar o mal estar no cotidiano, adaptando-se a ele, como o manejo do sofrimento psíquico pelo capitalismo tenta fazer. Freud não duvida de que o homem busque a felicidade. Contudo, adverte que, para esta felicidade, não há nada programado. $\mathrm{O}$ prazer, como aquilo que encadeia o homem na dimensão de sua verdade traz o caráter do fictício. Toda verdade possui uma estrutura de ficção, o que não deve ser reduzida a enganação, mas que diz respeito ao simbólico. São inclusive a partir daí, pela formula da fantasia e da noção de desejo como desejo do Outro, que irão se produzir as organizações ficcionais do desejo É por isso que a satisfação do desejo nem sempre traz prazer, o que mostra que o sujeito não se relaciona com seu desejo de modo unívoco, muitas vezes o rejeitando e censurando, não o assumindo. Neste sentido, cada homem delimita para si um ethos, construído a partir de seu encontro com o desejo do Outro e da ficção que o constituiu enquanto sujeito desejante. Assim, não há palavras que comportem a variedade de 
si, buscada numa existência concreta, nem, tampouco, uma lei universal que a defina, porque, no fim das contas, o confronto com esta verdade, a princípio libertadora, implica a sonegação de si mesmo (Lacan, 2008b).

A experiência moral em questão na análise é o confronto ao imperativo do real, das possibilidades de referenciamento do homem em relação ao real, em detrimento ao domínio do ideal e da suposição de um bem supremo. Deste modo temos que a instancia moral presentifica o real. Assim, a questão ética na práxis analítica não equivale a tentativa de penetrar no problema de delimitar a ação reta e correta relevante a condição humana (Lacan, 2008b).

Deste modo, inferimos que, no fundo, o que faz com que a psicanálise nunca tenha sido efetivamente refutada pela ciência médica, o que faz com que na história da ciência, ela não figure como equívoco, é o fato de a mesma não operar com os critérios de demonstração objetiva da verdade científica. $\mathrm{Na}$ intervenção psicanalítica, trata-se antes de mais nada de um engajamento do sujeito, especialmente, sua qualificação ética, radicalmente distinta de uma moral. Ele deve se preparar para o confronto com sua verdade, não tanto pelo acumulo de informações e conhecimentos produzidos pela associação livre, quanto pelo fato que passou pelo ritual requerido de encontro com sua fantasia fundamental e a posição de ficção e "mentira" que esta apresenta.

Além do mais, o essencial em psicanálise não é, afinal de contas, a aquisição de certo resultado, ou seja, a posse de um saber sobre si, possível graças a decifração do inconsciente. Seu irredutível é a encenação, na posição de linguagem, pela qual cada sujeito reconta suas estórias, de certo número de experiências e acontecimentos, a partir dos quais haverá a verdade que aparecerá ou passará como algo a apreender, num momento dado de apropriação de si, de modo enigmático e imaterializável, a partir de seus efeitos em seu discurso. Isso, na verdade, é o que torna o saber psicanalítico um saber que se perde sempre e, por isso, não pode ter as mesmas regras de validação de um saber do tipo cientifico.

A psicanálise recomeça sempre, ou seja, é no encontro com o um a um e o não saber que o habita que ela constitui seu saber. É assim, que sua ética convoca cada um, por si mesmo, a recomeçar todo o percurso tomando a si mesmo como um enigma, afinal, nenhum analista apoia sua escuta nos atendimentos precedentes. O interessante a destacar é que, embora tenha constituído para si um corpo teórico sólido, o saber psicanalítico não se reduz a uma aplicação mediante o acumulo de estudos e pesquisas, tanto para o psicanalista, como para quem dela se serve, o analisando. Ora, o enigmático que este saber anuncia somente é capturado, precisamente, por aquele que tenha passado por seus procedimentos rituais. É a partir daí que produzirá algo ou não se produzirá. $\mathrm{E}$ o acesso a este enigmático será perdido de novo, podendo ser novamente apreendido ou não apreendido por aqueles que neste caminho do desconhecido queiram se aventurar. Pois bem, tudo isso faz parte de uma tecnologia da verdade que nada tem a ver com a tecnologia da verdade produzida pela ciência.

\section{Referências}

Albuquerque, K. M. (2015). Freud, a racionalidade médica e a construção do objeto psicopatológicona psicanálise: um estudo epistemológico. Estudos

Interdisciplinares em Psicologia, 6(1), p. 54-64. Recuperado de http://dx.doi.org/10.5433/22366407.2015v6n1p54.

Arenas, A. (2011). La salud de todos sinlasegregacion de cada uno. In: Glaze, A, Brisset, F. O. B, \&Monteiro, M. E. D. (orgs.). (2011). A saúde para todos, não sem a loucura de cada um: perspectivas da psicanálise. Rio de Janeiro, RJ: Wak Editora.

Assoun, P.L. (1996). Metapsicologia 
freudiana: uma introdução. (D. D. Estrada trad.). Rio de Janeiro, RJ: Jorge Zahar.

Benoit, P. (1988). Psicanálise e medicina: teoria e casos clínicos. Rio de Janeiro: Jorge Zahar.

Cancina, P. H. (2008). La investigatión em psicoanálisis. Rosário: Argentina: Homo Sapiens Ediciones.

Caponi, S. (2012a). Loucos e degenerados: uma genealogia da psiquiatria ampliada. Rio de Janeiro: Editora Fiocruz.

Caponi, S. (2012b). Classificar e medicar: a gestão biopolítica dos sofrimentos psíquicos. Interthesis, 9(2), p. 101-122.

Recuperado de http://dx.doi.org/10.5007/18071384.2012v9n2p101

Caponi, S. (2009). Biopolítica e medicalização dos anormais. Physis: Revista de Saude Coletiva, 19(2), p. 529-549. Recuperado de http://dx.doi.org/10.1590/S010373312009000200016

Castro, E. (2016). Vocabulário de Foucault: um percurso sobre seus temas, conceitos e autores. Belo Horizonte: Autêntica.

Clavreul, J. (1983). A ordem médica: poder e impotência do discurso médico. São Paulo: Editora Brasiliense.

Dunker, C. (2011). Estrutura e constituição da clínica psicanalítica: uma arqueologia das práticas de cura, psicoterapia e tratamento. São Paulo: Annablume.

Ehrenberg, A. (2004). Les Changement de la Relation Normal - Pathologique. Revue Esprit, p.133-156, Paris: France.

Fink, B. (1998). O sujeito lacaniano: entre a linguagem e o gozo. (M. L. D. Sette trad.). Rio de Janeiro, RJ: Jorge Zahar.

Foucault, M. (2010a). Os anormais: curso no Collège de France (1974-1975) (E. Brandão, trad.). São Paulo: Martins Fontes.

Foucault, M. (2010b). Em defesa da sociedade. (1975-76). (M. E. Galvão trad.). São Paulo: Martins Fontes.

Foucault, M. (2010c). Crise da medicina ou crise da antimedicina. Verve, 18(1), p. 167194.

Foucault, M. (2006a). O poder psiquiátrico: curso dado no Collège de France (19731974). Trad. E. Brandão. São Paulo: Martins Fontes.

Foucault, M. (2006b). A hermenêutica do sujeito. Curso dado no College de France (1981-1982). Trad. M. A. Fonseca. São Paulo: Martins Fontes

Foucault, M. (1995). Sujeito e poder. In: H. L. Dreyfus; P. Rabinow. Michel Foucault: uma trajetória filosófica: para além do estruturalismo e da hermenêutica. (pp. 231249). Rio de Janeiro: Forense Universitária.

Foucault, M. (1988). História da sexualidade I: a vontade de saber. (13 ${ }^{\mathrm{a}}$ edição). (M. T C. Albuquerque trad.) Rio de Janeiro: Edições Graal.

Foucault, M. (1984). O nascimento da medicina social. In: Foucault, $\mathrm{M}$. Microfísica do poder. (p. 79-98). (R. Machado trad.) Rio de Janeiro: Edições Graal.

Freud, S. (1996a). Totem e tabu. In: Edição standard brasileira das obras psicológicascompletas de Sigmund Freud, Vol. XIX. Rio de Janeiro: Imago. (Trabalho originalmente publicado em 1913).

Freud, S. (1996d). O mal estar na civilização. In: Edição standard brasileira das obras psicológicas completas de Sigmund Freud, Vol. XXIII. Rio de Janeiro: Imago. (Trabalho originalmente publicado em 1930).

Fuks, B. B. (2007). Freud e a cultura. Rio de janeiro, RJ: Jorge Zahar.

Gaspard, J. L. (2012). Discurso médico e clínica psicanalítica: colaboração ou subversão. In: Rudge, A. M., \&Besset, V. (orgs.). (2012). Psicanálise e outros saberes. Rio de Janeiro: Cia de Freud.

Gori, R. \& Del Volgo, M.J. (2009). La santétotalitaire; essaisurlamédicalisation de l'existence. Paris: Champs Essais.

Lacan, J. (2010). O seminário livro 3 as psicoses. Rio de Janeiro: JZE.

Lacan, J. (2008a). A ciência e a verdade. In: Lacan, J. (2008). Escritos. Rio de Janeiro: Jorge Zahar.

Lacan, J. (2008b). O seminário livro 7 a ética da psicanálise. Rio de Janeiro: JZE. 
Lacan, J. (1998). O seminário livro 11 os quatro conceitos fundamentais da psicanálise. Rio de Janeiro: JZE.

Le Blanc, G. (2007). Les maladies de l'homme normal. Paris: J. Vrin.

Lins, M. I. (1996). O saber psicanalítico: uma questão também de ética. In: França, M. I. (org.). Ética, psicanálise e sua transmissão. Petrópolis, RJ: Vozes.

Machado, R. (2007). Foucault, a ciência e o saber. Rio de Janeiro: Zahar.

Miller, J.A. (2011). Saúde mental e ordem pública. In: Glaze, A, Brisset, F. O. B, \&Monteiro, M. E. D. (orgs.). (2011). A saúde para todos, não sem a loucura de cada um: perspectivas da psicanálise. Rio de Janeiro, RJ: Wak.

Ventura, R. (2012). A psicanálise e o cuidado de si: entre a sujeição e a liberdade. Revista EPOS, 3(2).

Dados sobre as autoras:

- Kelly Moreira de Albuquerque é doutora em Psicologia pela Universidade de Fortaleza UNIFOR. Mestre em Psicologia (UFC). Graduação em Psicologia (UNIFOR). Docente do curso de graduação em Psicologia da Fanor-Devry Brasil. Membro do grupo de estudos foucaultianos Vontade de Saber, vinculado ao Laboratório de estudo em psicanálise, cultura e subjetividade LAEPCUS.

- Clara Virginia de Queiroz Pinheiro é doutora em Saúde Coletiva pela Universidade do Estado do Rio de Janeiro - UERJ. Pósdoutorado no CNRS/CERME3/Université Paris-Descartes. Professora titular do Programa de Pós Graduação em Psicologia da Universidade de Fortaleza. Membro do GT/AMPEPP Dispositivos clínicos em saúde mental e membro/fundadora do Laboratório de Estudos em Psicanálise, Cultura e Subjetividade - LAEPCUS. Membro do grupo de estudos foucaultianos Vontade de Saber. 